\title{
Microstructure and Characteristic of Laser Surface Alloyed Ni and Ni-Cr-B-Si on Al-Mg-Si Alloy
}

\author{
Yao-Chih Chuang ${ }^{1, *}$, Shih-Chin Lee ${ }^{1}$ and Hsin-Chih Lin ${ }^{2}$ \\ ${ }^{1}$ Department of Materials Science and Engineering, National Cheng Kung University, Tainan, Taiwan, R. O. China \\ ${ }^{2}$ Department of Materials Science and Engineering, National Taiwan University, Taipei, Taiwan, R. O. China
}

A $5 \mathrm{KW} \mathrm{CO} 2$ laser has been used to modify the surface microstructure of $\mathrm{Al}-\mathrm{Mg}-\mathrm{Si}$ aluminum alloy with pure $\mathrm{Ni}$ and $\mathrm{Ni}-\mathrm{Cr}-\mathrm{B}-\mathrm{Si}$ powders. The experimental results indicate that a porosity-free zone can be generated after laser surface alloying (LSA). The $\mathrm{Al}_{3} \mathrm{Ni}$ particles were only observed in the LSA Ni sample. In the LSA Ni-Cr-B-Si sample, there are three regions indicated as surface region in the melt zone (region A), bottom region in the melt zone (region $\mathrm{B}$ ), and amorphous phase in bottom region (region $\mathrm{C}$ ) from the top to the bottom. In the region $\mathrm{A}$, the $\mathrm{Al}_{3} \mathrm{Ni}$ particles are present and the $\mathrm{Al}_{3} \mathrm{Ni}_{2}$ particles distributed in the region $\mathrm{B}$. The partial $\mathrm{Al}-\mathrm{Ni}-\mathrm{Cr}$ amorphous structures are dispersed in the region $\mathrm{C}$. And, the $\mathrm{AlNi}$ and $\mathrm{Al}_{8} \mathrm{Cr}_{5}$ structures were observed in the interface of region $\mathrm{B}$ and $\mathrm{C}$. The hardness of the LSA Ni$\mathrm{Cr}-\mathrm{B}-\mathrm{Si}$ sample is sharply increased than Al-matrix and Ni specimen, specifically the amorphous structure in region $\mathrm{C}$ is about 18 times higher than the Al-matrix.

(Received September 22, 2005; Accepted November 10, 2005; Published January 15, 2006)

Keywords: laser surface alloying (LSA), nickel-chromium-boron-silicon powders, amorphous structure

\section{Introduction}

Aluminum alloys have been used extensively in many industries because of their excellent properties, such as high thermal conductivity, excellent workability and high specific strength. But some drawbacks, like low hardness, poor tribological properties and crevice corrosion resistance, still need to be improved. In the past decades, a considerable number of studies have been made on how to improve the surface properties of aluminum alloys, involving the electroplating, chemical plating, anodizing and thermal spraying. ${ }^{1-3)}$ However, these surface treatments are conventional techniques of low productivity, exhausting energy and intensive manpower. Recently, laser surface alloying (LSA) is successfully developed to improve the surface properties of various metals and alloys. LSA involves the processes of rapid melting, intermixing and solidification with different metals or ceramics. During the LSA process, several features need to be carefully controlled, such as the heat transfer, concentration gradient geometry and material segregation in the non-stationary condition. In fact, many researchers have carried out these studies and find that the LSA can indeed improve the surface mechanical/chemical properties of wear, ${ }^{4-7)}$ corrosion $^{8,9)}$ and cavitation erosion resistance. ${ }^{10,11)}$

The powder $(\mathrm{Ni}-\mathrm{Cr}-\mathrm{B}-\mathrm{Si})$ is commercially available and is often used on the surface treatments of ferrous alloys because of its several advantages, such as low melting temperature and high hardness. This powder has been successfully laser-clad or laser surface alloyed onto steels, ${ }^{12)}$ titanium alloys ${ }^{13)}$ and aluminum alloy. ${ }^{14)}$ One may notice that the Ni element in this powder has the same crystal lattice with $\mathrm{Al}$, and hence the intermetallic compounds of $\mathrm{Al}_{3} \mathrm{Ni}, \mathrm{Al}_{3} \mathrm{Ni}_{2}$, AlNi and $\mathrm{Ni}_{3} \mathrm{Al}$ are easily formed during the processes of laser cladding or laser surface alloy. ${ }^{15}$ It has also been reported that the plasma-sprayed and laser-melted $\mathrm{Ni}-\mathrm{Cr}-\mathrm{B}-$

*Graduate Student, National Cheng Kung University; Corresponding author, E-mail: MAXWELL@cubic.mse.ncku.edu.tw
Si layers have very fine grains and high hardness. ${ }^{16)}$ However, to the authors' best knowledge, there is no systematic investigation on the LSA $\mathrm{Ni}-\mathrm{Cr}-\mathrm{B}-\mathrm{Si}$ on the $\mathrm{Al}-\mathrm{Mg}-\mathrm{Si}$ alloys. More experiments are necessary to be carried out to clarify the LSA characteristics on these aluminum alloys.

In this study, the pure $\mathrm{Ni}$ and $\mathrm{Ni}-\mathrm{Cr}-\mathrm{B}-\mathrm{Si}$ powders are laser surface alloyed on the $\mathrm{Al}-\mathrm{Mg}-\mathrm{Si}$ alloys. The microstructures and surface properties of these LSA layers are systematically studied and compared. Meanwhile, the effect of $\mathrm{Cr}$ element on the laser-treated $\mathrm{Ni}-\mathrm{Cr}-\mathrm{B}-\mathrm{Si}$ layers is also discussed.

\section{Experimental Procedure}

The chemical compositions of the substrate material are shown in Table 1 . The samples were machined into $80 \times$ $20 \times 5 \mathrm{~mm}^{3}$ rectangular plates. Before LSA, the samples were sand blasted to increase the surface roughness and reduce the reflectivity of the laser beam. The chemical compositions of the $\mathrm{Ni}-\mathrm{Cr}-\mathrm{B}-\mathrm{Si}$ powder are shown in Table 2.

LSA was conducted with a $5 \mathrm{~kW}$ continuous transverse flow $\mathrm{CO}_{2}$ laser. The laser beam diameter was $2.5 \mathrm{~mm}$, the

Table 1 The chemical compositions of Al-Mg-Si alloys used in this study. (in $\operatorname{mass} \%$ )

\begin{tabular}{ccccccc}
\hline Element & $\mathrm{Al}$ & $\mathrm{Mg}$ & $\mathrm{Si}$ & $\mathrm{Fe}$ & $\mathrm{Cu}$ & $\mathrm{Zn}$ \\
\hline & Bal. & 1.0 & 0.6 & 0.7 & 0.27 & 0.15
\end{tabular}

Table 2 The chemical compositions of LSA powder used in this study. (in mass\%)

\begin{tabular}{cccccccc}
\hline Element & Ni & Cr & B & Si & Fe & C \\
\cline { 1 - 5 } LSA powder & & & & & & \\
\hline Ni-Cr-B-Si & Bal. & 14.64 & 3.21 & 4.32 & 3.65 & 0.73 \\
\hline
\end{tabular}


power density of the laser beam was $7.13 \times 10^{4} \mathrm{~W} / \mathrm{cm}^{2}$ and the laser scanning velocity was $10 \mathrm{~mm} / \mathrm{s}$. The sample surface was protected by argon gas during LSA. The powders were delivered to the pool with a flowing rate of about $2 \mathrm{~g} / \mathrm{min}$ by a powder feeding system, which own gravity without assistance from the argon gas. After LSA, the cross-section of the samples was carefully cut perpendicular to the direction of laser scanning. A foil thickness of $1.0 \mathrm{~mm}$ was cut from below the surface for TEM observation. After reducing the thickness to 20 um by grinding, TEM'specimen was made by ion miller. The observation and analysis of microstructure were made by a Hitachi S-4200 scanning electron microscope (SEM) and high resolution of Hitachi HF-2000 field emission transmission electron microscope (TEM). The compositions were analyzed by an EDS attached to the SEM with a probe size on the order of $10 \mathrm{~nm}$ and resolution of $1 \mu \mathrm{m}$. The hardness was measured by a Vickers Hardness Tester with a load of $50 \mathrm{~g}$ for $15 \mathrm{~s}$. For each specimen, the average hardness value was calculated from at least five test readings.

\section{Results and Discussion}

Figure 1(a) shows the cross-section of the LSA Ni on Al$\mathrm{Mg}-\mathrm{Si}$ alloy. It is found that the porosity-free zone can be achieved but some cracks appear after LSA. Although Fu et al. ${ }^{17)}$ demonstrated that the addition of $\mathrm{Ni}$ element in the melted coating can reduce the cracking susceptibility and prevent the crack formation. But some cracks still appear in the LSA Ni on Al-Mg-Si alloy, as shown in Fig. 1(a). The result of the experiment is that the microstructure of the LSA $\mathrm{Ni}$ on $\mathrm{Al}-\mathrm{Mg}-\mathrm{Si}$ alloy has the same form. A close look at the microstructure is shown in Fig. 1(b), which is taken $0.5 \mathrm{~mm}$ depth from the surface of the pool in Fig. 1(a). As shown in Fig. 1(b), lots of precipitated particles are observed. These particles seem to precipitate along the grain boundaries of $\mathrm{Al}-\mathrm{Mg}-\mathrm{Si}$ matrix. The chemical compositions of these precipitated particles, which is the magnification of an arrow tip, are analyzed by EDS. The chemical compositions of precipitated particles are measured in $89.3 \% \mathrm{Al}, 9.1 \% \mathrm{Ni}$, $0.4 \% \mathrm{Mg}, 0.7 \% \mathrm{Si}$ and $0.5 \% \mathrm{Cu}$ (in mass $\%$ ) by SEM/EDS.

These precipitated particles are $\mathrm{Al}_{3} \mathrm{Ni}$ compounds according to the binary phase diagrams of $\mathrm{Al}-\mathrm{Ni} .{ }^{15)}$ More noteworthy is the content of $\mathrm{Ni}$ element be remained about 4.2 (in mass\%). It is obvious that the less $\mathrm{Ni}$ element is melted into the $\mathrm{Al}-$ $\mathrm{Mg}-\mathrm{Si}$ alloy by LSA. Later, we shall try to give amore precise account of the Ni element is less in the LSA Ni sample. Although Fu et al. ${ }^{17)}$ don't define how much content of the Ni element can be prevent the formation of the cracks. However, it seems to suppose that the content of the $\mathrm{Ni}$ element is not enough to completely remove cracks in the LSA Ni specimen.

Figure 2 shows the cross-section of the LSA Ni-Cr-B-Si on $\mathrm{Al}-\mathrm{Mg}-\mathrm{Si}$ alloy. No cracks are observed in Fig. 2 and the morphology seems more complex than that in Fig. 1(a) for the LSA Ni sample. To avoid confusion, the three distinct regions indicated as surface region in the melt zone (region A), bottom region in the melt zone (region B), and amorphous phase in bottom region (region $\mathrm{C}$ ) in Fig. 2, are observed for the LSA Ni-Cr-B-Si sample. The SEM
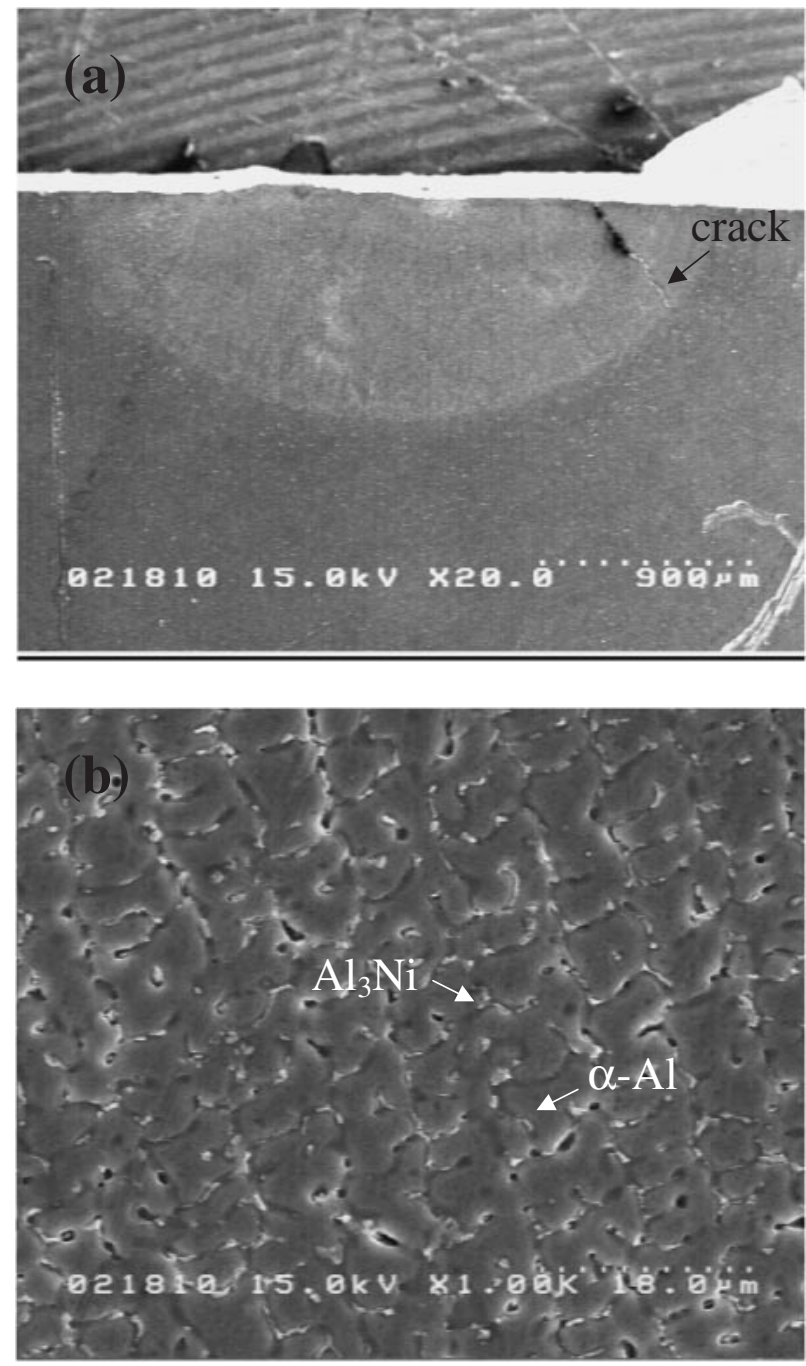

Fig. 1 SEM photographs of the LSA Ni sample: (a) cross-section of the pool; (b) microstructure of the precipitated particles.

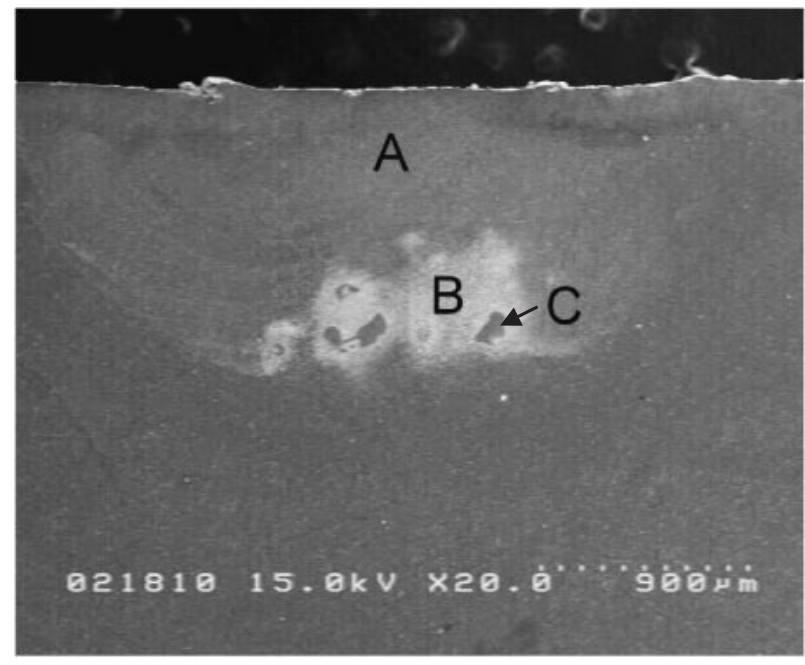

Fig. 2 The cross-section of the LSA Ni-Cr-B-Si sample.

observations of regions A and B in Fig. 2 are shown in Fig. 3(a) and (b), respectively. The eutectic microstructures with elongated particles in Fig. 3(a) and needle-like particles 

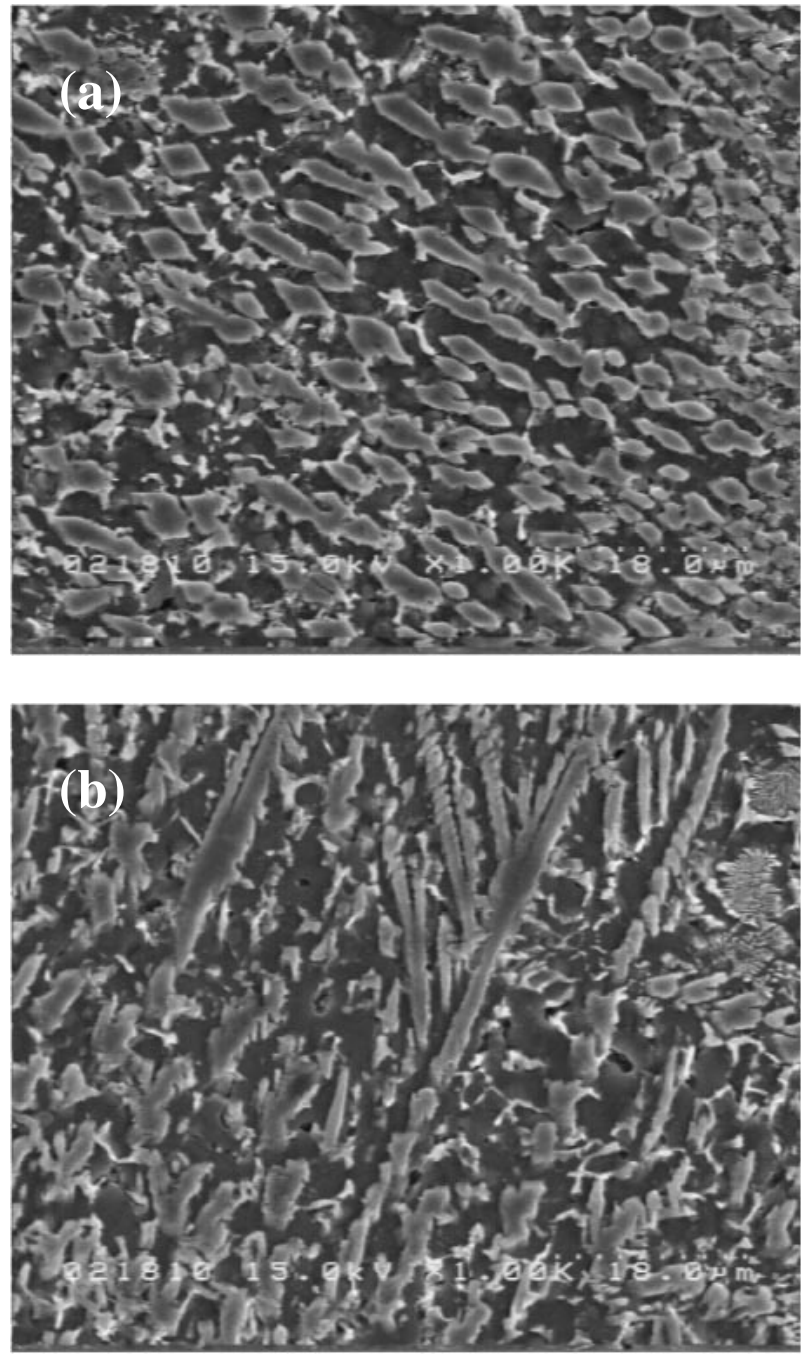

Fig. 3 SEM photos of the LSA Ni-Cr-B-Si sample: (a) region A; (b) region $\mathrm{B}$.

in Fig. 3(b) are clearly observed. The chemical compositions of these elongated particles are analyzed by EDS as follows; $88.9 \% \mathrm{Al}, 10.0 \% \mathrm{Ni}, 0.5 \% \mathrm{Mg}$ and $0.6 \% \mathrm{Si}$ (in mass \%). On the other hand, the chemical compositions of these needle-like particles are analyzed by EDS as follows; $71.4 \% \mathrm{Al}$, $27.7 \% \mathrm{Ni}, 0.3 \% \mathrm{Mg}$ and $0.6 \% \mathrm{Si}$ (in mass $\%$ ). As calculated the rough atomic ratio of $\mathrm{Al} / \mathrm{Ni}$ from the data, the elongated particles and the needle-like particles are about 3 and 1.5, respectively. Hence, the elongated particles in Fig. 3(a) are $\mathrm{Al}_{3} \mathrm{Ni}_{\mathrm{i}}$ compounds and the needle-like particles in Fig. 3(b) are $\mathrm{Al}_{3} \mathrm{Ni}_{2}$ compounds according to the binary phase diagrams of $\mathrm{Al}-\mathrm{Ni} .{ }^{15}$ ) These features indicate that the outer region $\mathrm{A}$ in the $\mathrm{LSA} \mathrm{Ni}-\mathrm{Cr}-\mathrm{B}-\mathrm{Si}$ sample has the same $\mathrm{Al}_{3} \mathrm{Ni}$ structure as that occurred in the LSA Ni sample, although the $\mathrm{Al}_{3} \mathrm{Ni}$ particles in $\mathrm{Ni}-\mathrm{Cr}-\mathrm{B}-\mathrm{Si}$ sample are much larger than that in $\mathrm{Ni}$ sample. As reported in the previous, ${ }^{16,18)}$ the $\mathrm{B}$ element can effectively reduce the melting temperature of $\mathrm{Ni}-\mathrm{Cr}-\mathrm{B}-\mathrm{Si}$ powder and the $\mathrm{Si}$ element can increase the fluidity of the pool during LSA process. These features can increase the reaction probability of $\mathrm{Al}-\mathrm{Ni}$ phases and hence, the quantity and particle size of $\mathrm{Al}_{3} \mathrm{Ni}$ structure in the LSA $\mathrm{Ni}-\mathrm{Cr}-\mathrm{B}-\mathrm{Si}$ sample are much higher than those in LSA Ni sample. In the inner region $\mathrm{B}$, the $\mathrm{Al}_{3} \mathrm{Ni}_{2}$ compound is the
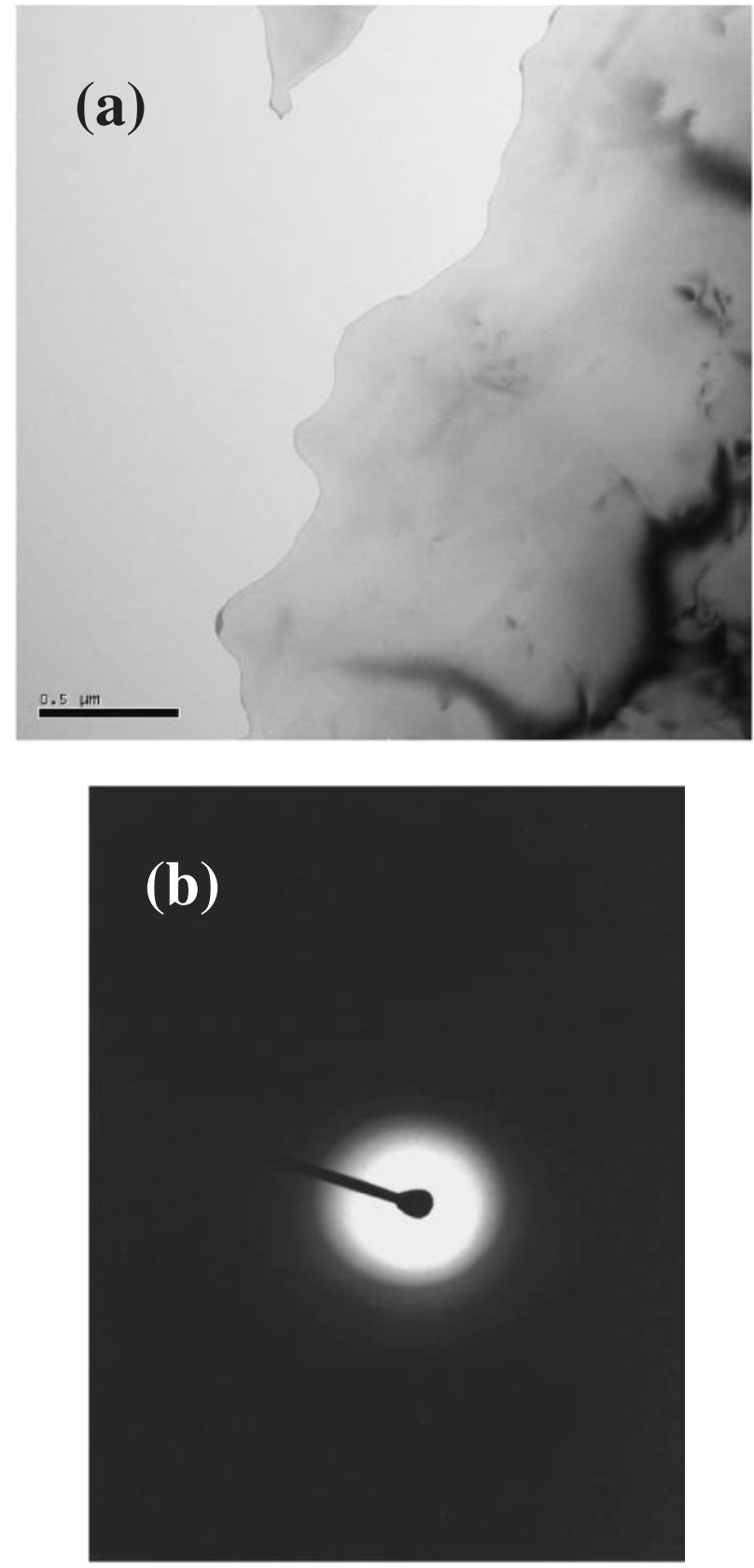

Fig. 4 TEM photographs of the region $\mathrm{C}$ in LSA Ni-Cr-B-Si sample: (a) the bridge field photograph; (b) the electron diffraction pattern.

main structure because the more slowly solidification rate lead to more $\mathrm{Ni}$ element can react with $\mathrm{Al}-\mathrm{Mg}-\mathrm{Si}$ matrix in this inner region. For reasons mentioned above, it can be explained the Ni element is less in the LSA Ni sample.

While the region $\mathrm{C}$ can be analyzed by SEM/EDS, the weak intensity was made the authenticity of the microstructure is doubtful. We support TEM analysis in order to understand the structure of region C. Figures 4(a), (b) shows the TEM micrograph and diffraction pattern of region $\mathrm{C}$ in Fig. 2. The diffraction pattern shown in Fig. 4(b) exhibits a typical amorphous structure. The chemical compositions of this amorphous structure are measured to be in the range of $44-47 \% \mathrm{Al}, 42-43 \% \mathrm{Ni}, 9-13 \% \mathrm{Cr}$ (in mass \%) by TEM/EDS. Although the chemical compositions were unable to decide, it should be concluded that is $\mathrm{Al}-\mathrm{Ni}-\mathrm{Cr}$ amorphous structure. 


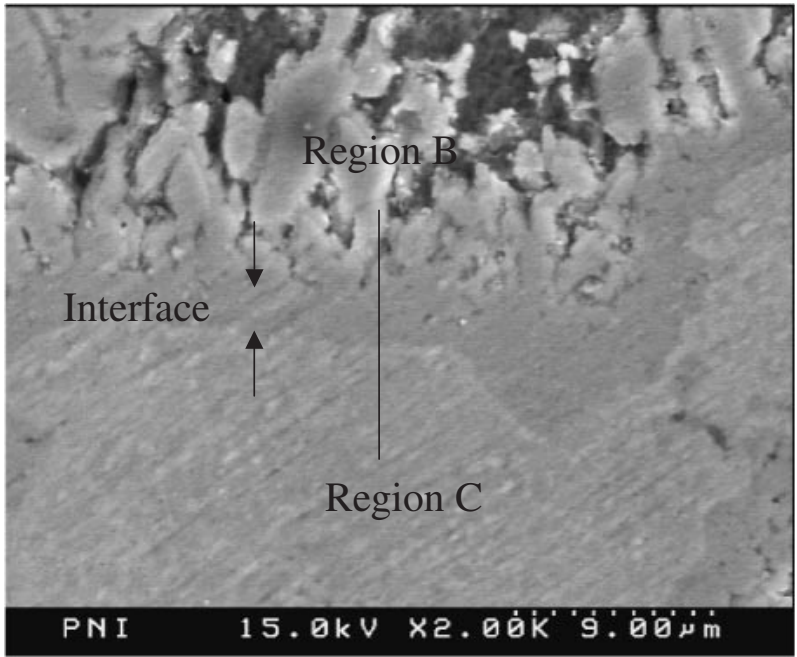

Fig. 5 SEM photograph of the interface region.

It has also been observed in the laser-treated $\mathrm{Ni}-\mathrm{Cr}-\mathrm{B}-\mathrm{Si}$ specimen by Liang et al. ${ }^{19)}$ In addition to the regions of $\mathrm{A}, \mathrm{B}$, $\mathrm{C}$, the interface between the region $\mathrm{B}$ and $\mathrm{C}$ is worthy to be more understood. Figure 5 exhibits a SEM micrograph showing the interface of region $\mathrm{B}$ and $\mathrm{C}$ with a thickness of about $4-5 \mu \mathrm{m}$. Figures 6 and 7 are showed the TEM micrographs and diffraction patterns of the particles in the interface. Figures 6(a), (b) show a TEM bright/dark field image of the interface, which many particles were existed in. The electron diffraction pattern, which is the magnification of an arrow tip in Fig. 6(b), is well indexed as the simple cubic structure (s.c.) with. According to the indexing of Fig. 6(c), the particles were found to be AlNi. Besides, tiny particles were cluster in the interface, which is closed to region $\mathrm{C}$, as shown in the Fig. 7. Figure 7(a) is the bright field image of the tiny particles and Fig. 7(b) is the diffraction pattern, which is the magnification of an arrow tip in Fig. 7(a). According to the indexing of Fig. 7(b), the particles are found to be $\mathrm{Al}_{8} \mathrm{Cr}_{5}$, which is rhombohedral structure.

Figure 8 shows the concentration profile of $\mathrm{Al}, \mathrm{Ni}$ and $\mathrm{Cr}$ elements versus the line from region $\mathrm{B}$ and $\mathrm{C}$, as the line in Fig. 5, of the LSA Ni-Cr-B-Si sample by EDX. From this figure, it is obvious that the content of $\mathrm{Ni}$ is increased from region $\mathrm{B}$ to the interface. It is due to depend on the cooling rate that can influence the diffusion gradient. The content of $\mathrm{Ni}$ is decreased and $\mathrm{Cr}$ is increased in the region $\mathrm{C}$. It is due to the atomic radius of $\mathrm{Cr}$ is very similar to $\mathrm{Ni}^{20)}$ They can form substitution solid solutions, in a large composition range, with $\mathrm{Ni}$. Thus, we can postulate that the $\mathrm{Cr}$ atom mainly replace $\mathrm{Ni}$ in $\mathrm{Al}-\mathrm{Ni}$ compounds. However, E. G. Noya et al. ${ }^{21)}$ also found the system $\mathrm{Ni}-\mathrm{Al}$ fail to amorphize at conventional RQ rates $\left(10^{5}-10^{6} \mathrm{~K} / \mathrm{s}\right)$. Hence we don't observe amorphous structure in the LSA Ni sample. And the same observations applied to the region A and B of the LSA $\mathrm{Ni}-\mathrm{Cr}-\mathrm{B}-\mathrm{Si}$ sample. They have the same characteristics, as we have seen, the Cr element doesn't exist in the LSA Ni sample and the region $\mathrm{A}$ and $\mathrm{B}$ of the LSA Ni-Cr-B-Si sample. But it is found in the region $\mathrm{C}$ of the LSA Ni-Cr-B$\mathrm{Si}$ sample that the $\mathrm{Cr}$ was concentrated on. It should be concluded, from what has been said above, that it maybe
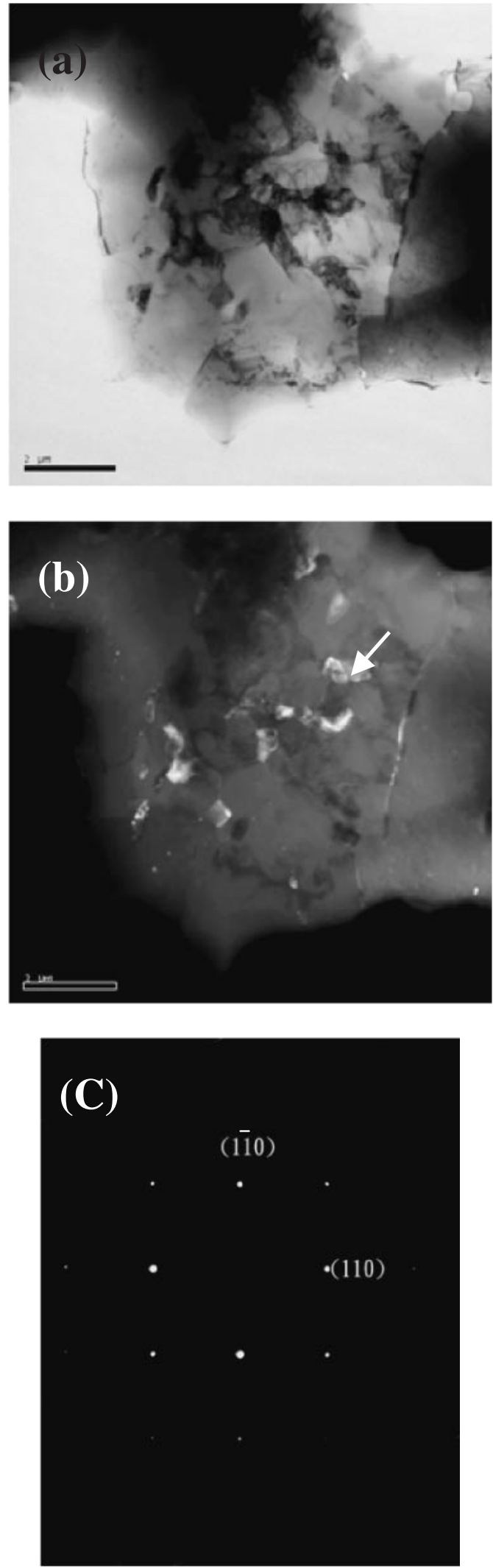

Fig. 6 TEM of the interface region: (a) the bridge field photograph of $\mathrm{AlNi}$; (b) the dark field photograph of AlNi; (c) the electron diffraction pattern of (b).

form amorphous structure in the region $\mathrm{C}$ of the LSA Ni-Cr$\mathrm{B}-\mathrm{Si}$ sample by $\mathrm{Cr}$ replacing with $\mathrm{Al}-\mathrm{Ni}$ compounds, as shown in the Fig. 4. 

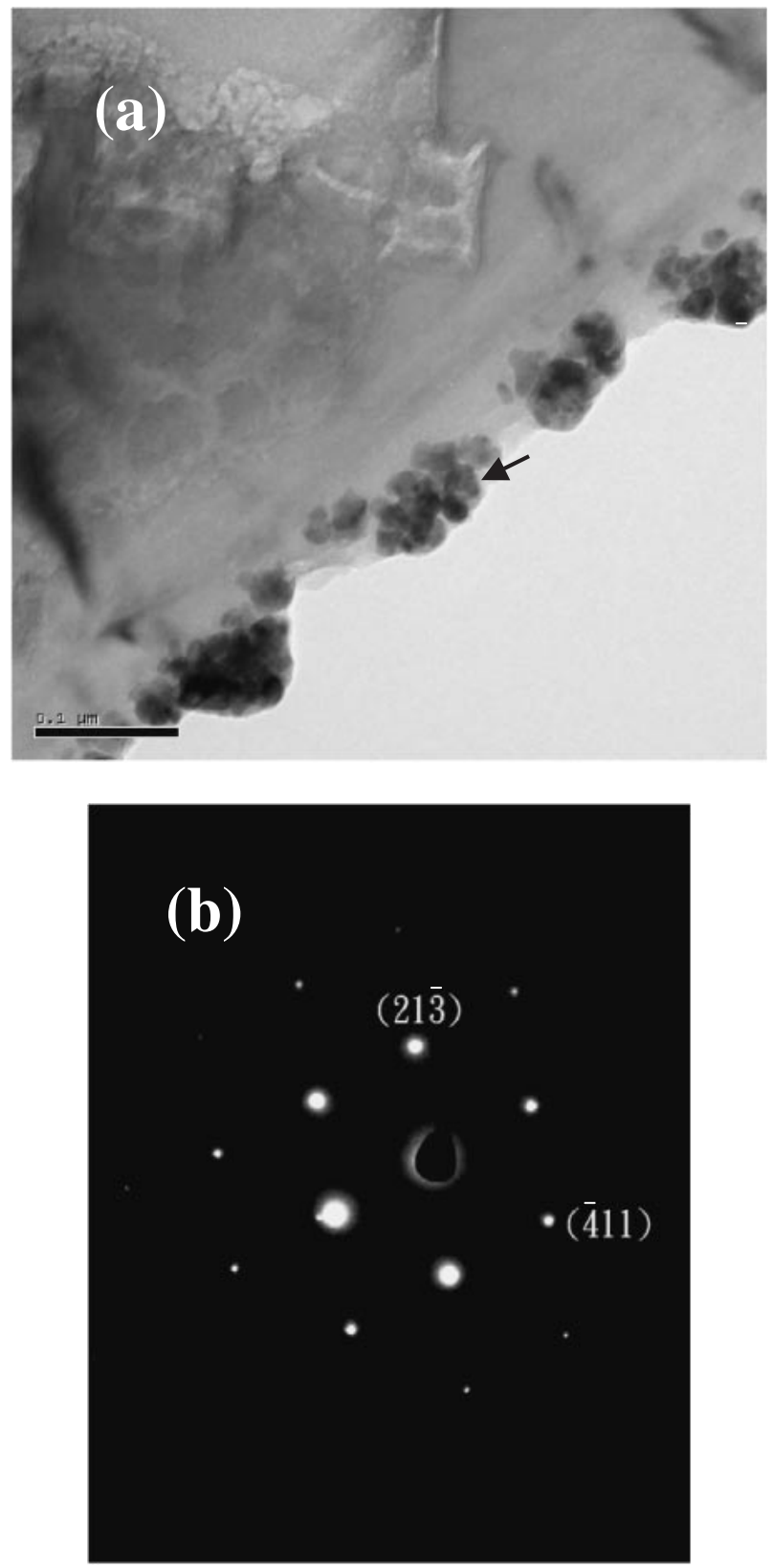

Fig. 7 TEM of the interface region: (a) the bridge field photograph of $\mathrm{Al}_{8} \mathrm{Cr}_{5}$; (b) the electron diffraction pattern of (a).

Table 3 Hardness of the Al-Mg-Si matrix, LSA Ni sample and LSA Ni$\mathrm{Cr}-\mathrm{B}-\mathrm{Si}$ sample.

\begin{tabular}{lccccc}
\hline & $\begin{array}{c}\text { Al-Mg-Si } \\
\text { matrix }\end{array}$ & $\begin{array}{c}\text { LSA Ni } \\
\text { sample }\end{array}$ & \multicolumn{3}{c}{$\begin{array}{c}\text { LSA Ni-Cr-B-Si } \\
\text { sample }\end{array}$} \\
\hline Position & & All pool & Region A & Region B & Region C \\
\hline Hardness (HV) & 60 & 67 & 179 & 535 & 1107 \\
\hline
\end{tabular}

Table 3 shows the hardness of the matrix, LSA Ni and Ni$\mathrm{Cr}-\mathrm{B}-\mathrm{Si}$ samples. The hardness of the LSA Ni sample is slight higher than Al-matrix, because it is only existed tiny $\mathrm{Al}_{3} \mathrm{Ni}$ particles, which almost can't markedly effect on the hardness. On the other hand, the hardness of the LSA Ni-Cr$\mathrm{B}-\mathrm{Si}$ sample is obvious higher than the Al-matrix and LSA $\mathrm{Ni}$ sample, because it is existed in a larger number and various $\mathrm{Al}-\mathrm{Ni}$ compounds (region $\mathrm{A}, \mathrm{B}$ and $\mathrm{C}$ ). The hardness

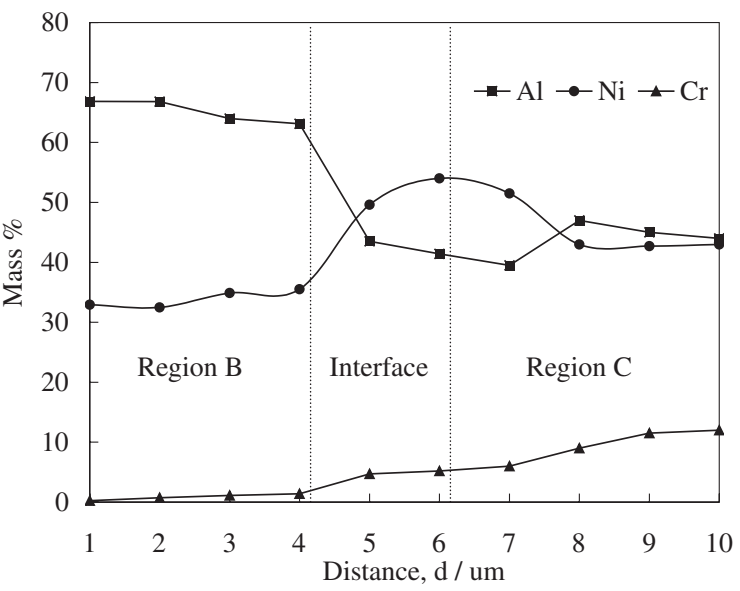

Fig. 8 Compositions distribution with distance from region $\mathrm{B}$ to $\mathrm{C}$ in LSA $\mathrm{Ni}-\mathrm{Cr}-\mathrm{B}-\mathrm{Si}$ sample.

of the region A is HV 180 and the region B is HV 535, which are approximately 3-9 times than the Al-matrix (HV 60). And, it indicates that hardness is increased with increasing of the contention of Ni. The highest hardness is occurred in region $\mathrm{C}$ that is the amorphous structure (about HV 1100), because of the greatest irregular arrangement of atoms on the structure in which large internal stress exists. The point to observe is that the $\mathrm{Cr}$ element not only enhances the hardness but also causes amorphize of region $\mathrm{C}$.

\section{Conclusions}

LSA $\mathrm{Ni}$ and $\mathrm{Ni}-\mathrm{Cr}-\mathrm{B}-\mathrm{Si}$ on the $\mathrm{Al}-\mathrm{Mg}-\mathrm{Si}$ alloy were investigated via the microstructural characterization, chemical composition and hardness testing. The following conclusions are considered as being important.

(1) The cracks are appeared in the LSA Ni on $\mathrm{Al}-\mathrm{Mg}-\mathrm{Si}$ alloy and is only found tiny $\mathrm{Al}_{3} \mathrm{Ni}$ particles in the pool. However, the $\mathrm{Al}_{3} \mathrm{Ni}$ aren't obvious increased the hardness.

(2) The microstructures of the LSA Ni-Cr-B-Si on Al$\mathrm{Mg}-\mathrm{Si}$ alloy are existed: (a) there are $\mathrm{Al}_{3} \mathrm{Ni}$ emerged in region $\mathrm{A}$, the $\mathrm{Al}_{3} \mathrm{Ni}_{2}$ existed in region $\mathrm{B}$ and the partial $\mathrm{Al}-\mathrm{Ni}-\mathrm{Cr}$ amorphous structure is found in region $\mathrm{C}$. (b) the $\mathrm{AlNi}$ and $\mathrm{Al}_{8} \mathrm{Cr}_{5}$ structures are occurred in the interface of region $\mathrm{B}$ and $\mathrm{C}$.

(3) It can't be observe amorphous structure in the LSA Ni sample. And the same observations applied to the region $\mathrm{A}$ and $\mathrm{B}$ of the $\mathrm{LSA} \mathrm{Ni}-\mathrm{Cr}-\mathrm{B}-\mathrm{Si}$ sample, which the $\mathrm{Cr}$ element doesn't exist. But the region $\mathrm{C}$ with amorphous structure of the LSA Ni-Cr-B-Si sample are existed a large amount of $\mathrm{Cr}$. One may say that the $\mathrm{Cr}$ maybe the primary element form the amorphous structure by LSA.

(4) The hardness of LSA Ni-Cr-B-Si sample is obvious higher than the matrix and the LSA Ni sample. The hardness was increased with increasing of the contention of $\mathrm{Ni}$ from the region A to region B. Especifically, the highest hardness was occurred in the region $\mathrm{C}$, which is about 18 times higher than the Al$\mathrm{Mg}-\mathrm{Si}$ matrix. 


\section{Acknowledgements}

The authors are pleased to acknowledge the financial support of this research by National Science Council (NSC), Republic of China, under grant no. NSC 89-2216-E-006-078.

\section{REFERENCES}

1) T. Suzuki, D. Huang and Y. Ikuhara: Surf. Coat. Technol. 107 (1998) 41-47.

2) X. D. Peng, A. Kharlov, V. Bystritski, E. Garate and E. J. Lavernia: Mater. Sci. Eng. A 251 (1998) 142-149.

3) K. Nakata and M. Ushio: Surf. Coat. Technol. 169-170 (2003) 443446.

4) L. J. Yang: Comp. Sci. Technol. 63 (2003) 575-583.

5) Qian Ming, L. C. Lin and Z. D. Chen: Surf. Coat. Technol. 106 (1998) 174-182.

6) Y. B. Liu, J. D. Hu, Z. Y. Cao and P. K. Rohatgi: Wear 206 (1997) 8386.

7) G. Y. Liang, T. T. Wong, J. M. K. MacAlpine and J. Y. Su: Surf. Coat. Technol. 127 (2000) 233-238.

8) T. M. Yue, Y. X. Wu and H. C. Man: Surf. Coat. Technol. 114 (1999) $13-18$.
9) H. C. Man, S. Zhang, T. M. Yue and F. T. Cheng: Surf. Coat. Technol. 148 (2001) 136-142.

10) W. J. Tomlinson and A. S. Bransden: Wear 185 (1995) 59-65.

11) K. F. Tam, F. T. Cheng and H. C. Man: Surf. Coat. Technol. 149 (2002) 36-44.

12) C. T. Kwok, F. T. Cheng, F. T. Cheng and H. C. Man: Surf. Coat. Technol. 107 (1998) 31-40.

13) R. L. Sun, D. Z. Yang, L. X. Guo and S. L. Dong: Surf. Coat. Technol. 132 (2000) 251-255

14) G. Y. Liang and T. T. Wong: Surf. Coat. Technol. 89 (1997) 121-126.

15) T. B. Massalski (Ed): Binary Alloy Phase Diagrams, ASM. Metal Park, Ohio. 1 (1986) 142.

16) T. T. Wong, G. Y. Liang and C. Y. Tang: J. Mater. Proc. Technol. 66 (1997) 172-178.

17) Y. Fu, A. W. Batchelor, Y. Gu, K. A. Khor and H. Xing: Surf. Coat. Technol. 99 (1998) 287-294.

18) A. Conde, F. Zubiri and y J. de Damborenea: Mater. Sci. Eng. A 334 (2002) 233-238.

19) G. Y. Liang, C. L. Li and J. Y. Su: Mater. Sci. Eng. A 224 (1997) 173176.

20) Colin J. Smithells: Metal Reference Book (5th Edition). (Butter-worth and Co. Ltd., London, 1976) 100.

21) E. G. Noya, C. Rey and L. J. Gallego: J. Non-Cryst. Solids. 298 (2002) $60-66$. 